\title{
A REVIEW OF SELECTED NEIGHBOURHOOD SUSTAINABILITY ASSESSMENT FRAMEWORKS USING THE BELLAGIO STAMP
}

\begin{tabular}{|r|l|}
\hline Journal: & International Journal of Building Pathology and Adaptation \\
\hline Manuscript ID & IJBPA-07-2018-0055.R2 \\
\hline Manuscript Type: & Original Article \\
\hline Keywords: & $\begin{array}{l}\text { Bellagio STAMP, Consensus approach, Sustainable neighbourhood, } \\
\text { Sustainability Assessment frameworks, Sustainability indicators }\end{array}$ \\
\hline \multicolumn{2}{|l}{} \\
\end{tabular}

SCHOLARONE $^{\text {m }}$
Manuscripts 
Table 1: Re-categorisation of the selected assessment tools into a single framework

\begin{tabular}{lllll}
\hline Category & BREEAM C & LEED ND & PCRS & Green STAR \\
\hline Governance & $9.3 \%$ & $2 \%$ & $2.1 \%$ & $14 \%$ \\
\hline $\begin{array}{l}\text { Economic } \\
\text { wellbeing }\end{array}$ & $14.8 \%$ & $1 \%$ & $1 \%$ & $21 \%$ \\
\hline Social wellbeing & $17.1 \%$ & $20 \%$ & $11.7 \%$ & $25 \%$ \\
\hline $\begin{array}{l}\text { Environment and } \\
\text { resource efficiency }\end{array}$ & $32.4 \%$ & $34 \%$ & $57.4 \%$ & $25 \%$ \\
\hline $\begin{array}{l}\text { Location, land use, } \\
\text { and site design }\end{array}$ & $12.6 \%$ & $31 \%$ & $22.6 \%$ & $12 \%$ \\
\hline Transportation & $13.8 \%$ & $12 \%$ & $6.2 \%$ & $3 \%$ \\
\hline Total & $100 \%$ & $100 \%$ & $100 \%$ & $100 \%$ \\
\hline
\end{tabular}


Table 2: Mandatory requirements in selected assessment frameworks

\begin{tabular}{|c|c|}
\hline $\begin{array}{l}\text { Neighbourhood } \\
\text { Sustainability } \\
\text { Assessment frameworks }\end{array}$ & Mandatory requirements \\
\hline $\begin{array}{l}\text { BREEAM Communities } \\
2012\end{array}$ & $\begin{array}{l}\text { G001-Consultation plan; GO02- Consultation and } \\
\text { engagement; SE01- Economic impact; SE02- Demographic } \\
\text { needs and priorities; SE03- Flood risk assessment; SE04- } \\
\text { Noise pollution; RE01- Energy strategy; RE02- Existing } \\
\text { buildings and infrastructure; RE03- Water strategy; LE01- } \\
\text { Ecology strategy; LE02- Land use; TM01- Transport } \\
\text { assessment. }\end{array}$ \\
\hline LEED-ND V4 2016 & $\begin{array}{l}\text { SLLP1- Smart location; SLLP2- Imperilled species; SLLP3- } \\
\text { Wetland and water body conservation; SLLP4- Agricultural } \\
\text { land conservation; SLLP5- Floodplain avoidance; NPDP1- } \\
\text { Walkable streets; NPDP2- Compact development; NPDP3- } \\
\text { Connected and open community; GIBP1- Certified green } \\
\text { building; GIBP2- Minimum building energy efficiency; } \\
\text { GIBP3- Indoor water use reduction; GIBP4- Construction } \\
\text { activity pollution prevention. }\end{array}$ \\
\hline PCRS 2010 & $\begin{array}{l}\text { IDPR1- Integrated development strategy; IDPR2- Sustainable } \\
\text { building guidelines; IDPR3- Community dedicated } \\
\text { infrastructure basic commissioning; NSR1- Natural system } \\
\text { assessment; NSR2- Natural system protection; NSR3- Natural } \\
\text { systems design and management strategy; LCR1- Plan 2030; } \\
\text { LCR2- Urban systems assessment; LCR3- Provision of } \\
\text { amenities and facilities; LCR4- Outdoor thermal comfort } \\
\text { strategy; LCR5- Minimum Pearl rated building within } \\
\text { communities; PWR1- Community water strategy; PWR2- } \\
\text { Building water guidelines; PWR3- Water monitoring and leak } \\
\text { detection }\end{array}$ \\
\hline $\begin{array}{l}\text { Green STAR } \\
\text { Communities }\end{array}$ & No mandatory requirements \\
\hline
\end{tabular}


Table 3: Target indicators to address context-specific urban challenges

\begin{tabular}{|c|c|c|c|}
\hline Country & $\begin{array}{l}\text { Assessment } \\
\text { framework }\end{array}$ & Core/local urban challenges & $\begin{array}{l}\text { Targeted indicators to address to local } \\
\text { urban challenges }\end{array}$ \\
\hline UK & & $\begin{array}{l}\text { Inadequate social wellbeing; } \\
\text { non engagement of citizens } \\
\text { in planning }\end{array}$ & $\begin{array}{l}\text { SE02- Demographic needs and priorities; } \\
\text { SE05- Housing provision; SE06- Delivery of } \\
\text { services, facilities, and amenities; SE07- } \\
\text { Public realm; SE09- Utilities; SE11- Green } \\
\text { infrastructure; SE12- Local parking; SE14- } \\
\text { Local vernacular; SE15- Inclusive design }\end{array}$ \\
\hline USA & LEED ND & $\begin{array}{l}\text { Urban sprawl; high } \\
\text { dependence on automobile; } \\
\text { urban heat Island }\end{array}$ & $\begin{array}{l}\text { NPD C1- Walkable streets; NPD C2- } \\
\text { Compact development; NPD C3- Mixed-use } \\
\text { neighbourhood centres; NPD C4- Mixed- } \\
\text { Income diverse communities }\end{array}$ \\
\hline UAE & PCRS & Limited water supply & $\begin{array}{l}\text { PW R1- Community water strategy; PW R2- } \\
\text { Building water guidelines; PW R3- Water } \\
\text { monitoring and leak detection; PW 1.1- } \\
\text { Community water use reduction: } \\
\text { landscaping; PW 1.2- Community water use } \\
\text { reduction: heat rejection; PW 1.3- } \\
\text { Community water use reduction: Water } \\
\text { features; PW 2: Storm water management; } \\
\text { PW 3: Water efficient buildings }\end{array}$ \\
\hline Australia & Green STAR & No consideration & No consideration \\
\hline
\end{tabular}




\title{
A REVIEW OF SELECTED NEIGHBOURHOOD SUSTAINABILITY ASSESSMENT FRAMEWORKS USING THE BELLAGIO STAMP
}

\begin{abstract}
Purpose

The Neighbourhood Sustainability Assessment Frameworks through which a proposed neighbourhood development can be evaluated against an array of sustainability indicators (SIs) began to gain prominence in the first decade of the 21st century. However, how these frameworks align with the Bellagio STAMP is an area yet to be examined by existing studies to inform their better development and usage in the delivery of sustainable neighbourhoods. The purpose of this paper is to review selected neighbourhood sustainability assessment frameworks using the Bellagio STAMP with the aim of identifying areas for improvement, while also exploring the possibilities of adopting the Bellagio STAMP as a consensus approach and reference to sustainability assessment at the neighbourhood level.
\end{abstract}

Design/methodology/approach

Adopting document analysis as a data collection method, the paper reviews BREEAM Communities; LEED-ND; PCRS; Green Star Communities using the Bellagio STAMP.

Findings

Findings from the study revealed that some of the selected assessment frameworks align partially with the Bellagio STAMP in their development while areas for improvement were identified.

\section{Research implications}

The study recommends that the Bellagio STAMP could offer helpful guidelines and procedure in conceptualising sustainability assessment at the neighbourhood level especially in developing countries where such a framework is yet to be conceived.

\section{Originality/value}

This study adds to the sustainability assessment literature by operationalising the Bellagio STAMP leading to its better understanding and application in sustainability assessment either in practice or in theory.

Keywords: Bellagio STAMP, consensus approach, sustainable neighbourhood, sustainability assessment frameworks, sustainability indicators.

\section{INTRODUCTION}

Sustainability discourse has continued to take the central stage in academic, professional, and government conferences (Komeily and Srinivasan, 2015). This is as a result of the urgency to ensure that, at all levels of spatial developments, there are places where people can live, work, and enjoy good quality of life, without any negative impact on the environment (Roberts 2009). Undoubtedly, the constraints of climate and demographic changes coupled with changes in social needs, and a decline in both natural and physical resources are also the driving forces in this campaign (Deakin and Curwell, 2004; Girardet, 2015; Lehmann, 2015). Consequently, the sustainability crusade birthed several initiatives, one of which is sustainability assessment which is a tool to direct decision towards sustainability (Hacking and Guthrie 2008). Since its emergence 
for use at the neighbourhood scale of spatial development, it has been the front banner in the campaign for urban sustainability in various context (Cashmore and Kornov, 2013; Berardi, 2013).

As sustainability assessment frameworks continue to play a crucial role in the campaign for urban sustainability, several principles have emerged in literature which are to serve as practical guidelines in developing an assessment framework practice-wise and in theory (Gibson, 2013; Reed, et al., 2006; Haapio, 2012; Hacking and Guthrie, 2008). Amongst these principles is the Bellagio STAMP which is the most widely recognised set of principles for sustainability assessment (Pinter, et al., 2012). While there have been few studies on the Bellagio STAMP (Sala et al., 2015; Pinter et al., 2012), no evidence in literature of a study to give an insight of how the Bellagio STAMP can be operationalized in terms of its application in the development and implementation of an assessment framework. This raises a question of its validity and applicability for conceptualising neighbourhood sustainability assessment frameworks. In addition, while several scholars (Sharifi and Murayama, 2013; Wangel et al., 2016) have reviewed some assessment frameworks, none of such reviews has been conducted using the Bellagio STAMP.

These two gaps led to this study which reviewed selected Neighbourhood Sustainability Assessment Frameworks using the Bellagio STAMP. This provided a better understanding and gave a practical insight of the Bellagio STAMP. Furthermore, as anticipated, this could lead to the adoption of the Bellagio STAMP to serve as a common reference for assessing sustainability at the neighbourhood level. The study is guided by these questions: (i) how well do existing assessment frameworks align with the Bellagio STAMP; (ii) can the Bellagio STAMP be adopted as a global methodological framework for sustainability assessment at the neighbourhood scale? The other sections of the paper are as follows: Section 2 presents the literature review; section 3 explains the methodology for the study while sections 4 , and 5 presents the results; discussion and conclusions of the study respectively.

\section{LITERATURE REVIEW}

\subsection{Sustainability Assessment and the Evolution of Neighbourhood Sustainability Assessment Frameworks}

Sustainability assessment frameworks emerged in the closing decades of the 20th century as one of the several initiatives to enhance urban sustainability. Sustainability Assessment according to Pope et al. (2004), Cashmore and Kornov (2013), and Sala et al. (2015) is traceable to both Environmental Impact Assessment (EIA) and the Strategic Environmental Assessment (SEA). It helps to identify, predict, and evaluate the likely impacts and consequences of wide range of initiatives and alternatives on sustainable development (Devuyst, 2000; AlWaer and Kirk, 2015). Sustainability Assessment has attracted appreciable interest and acceptance through its usage, most especially its application for decision-making at the neighbourhood level. With an assessment framework, master plans of new neighbourhood development can now be evaluated against a number of predefined sustainability criteria or indicators (Wangel, et al., 2016). Its application at the neighbourhood level which emerged around a decade ago, was propelled by three main factors. (i) One, Agenda 21 which called for the community involvement of local stakeholders in visioning sustainability. Two, the need to enlarge the scale of assessment from the building scale to the 
neighbourhood level. Three, the strategic position and roles of neighbourhoods as the planning units and building blocks of cities and urban areas (Adewumi, et al., 2017; Berardi, 2013).

Although a neighbourhood sustainability assessment framework is still overwhelmingly used for the appraisal of sustainability of the design and development plans of new-medium and large-scale neighbourhoods (AlWaer, et al., 2014; Sharifi and Murayama, 2013; Warren-Myers, 2018), it has found applications beyond assessment purposes, as it is now being used for certification. It is gradually becoming the standards for the definition of sustainability in the built environment at the neighbourhood level (Berardi, 2011). It can be used as a development guide in shaping sustainable neighbourhoods (Yigitcanlar, et al., 2015). Beyond these, it can be used as a tool for urban neighbourhood regeneration (AlWaer, et al., 2014), performance assessment, and a tool to promote community engagement (Joss, et al., 2015).

Consequently, several sustainability assessment frameworks dedicated for use at the neighbourhood scale of spatial development have been developed in various nations of the world to drive urban sustainability. Pioneering the movement of Neighbourhood Sustainability Assessment Framework was the development of HQE2R between 2001 and 2004 and Earth craft communities in 2003. Subsequently, in 2006-2009, the CASBEE-UD, the U.S. Star community Rating System (STAR-CRS), LEED Neighbourhood Development (LEED -ND), and the UK BREEAM communities (BREEAM-C) were launched. Most recently, the German system DGNB New Urban Districts and the Australian system Green Star Communities were launched in 2011 and 2012 respectively (Wangel, et al., 2016). Some of which are briefly explained:

BREEAM Communities: The BREEAM family which originated in 1990 with success already recorded at the building scale developed and released the BREEAM communities in 2009 for neighbourhood planning and design. The current version was released in 2012. The development of BREEAM Communities was an advancement of the vision of the existing BREEAM assessment tool as it attempts to evaluate holistically the sustainability of a proposed development using the social, economic, and environmental dimensions of sustainability (BRE, 2012).

LEED ND: The US Green Building Council, Congress for the New Urbanism (CNU), and the Natural Resource Defense Council (NRDC) developed the LEED Neighbourhood development in 2008 with the recent version released in 2016. The vision of LEED ND is to enhance smart growth, and new urbanism in addition to green infrastructure and buildings. This, is to promote durable, healthy, affordable, environmentally responsive practices in building design and construction (USGBC, 2016).

Green Star Communities: The Green star community assessment was developed by the Green Building Council of Australia (GBCA) in 2012 as a natural framework, and as a rating tool to enhance liveability, local economic prosperity and the delivery of sustainable neighbourhoods (GBCA, 2012). Since its development, it has found wide application in strategic planning, master planning, town planning, development control, social planning sustainability and environment, economics, and asset management.

Pearl Community Rating System: The PCRS for Estidama is the assessment tool developed by the Abu Dhabi Urban Planning Council (AUPC). 'Estidama' is the Arabic translation for sustainability. The assessment framework was established in 2010 to transform the nation of Abu 
Dhabi into a symbol of sustainability. The rating system is with a core vision of achieving the four dimensions of 'Estidama' which are economic, social, cultural and environmental issues (AUPC, 2010).

\subsection{The Bellagio STAMP}

To develop a sustainability assessment frameworks, certain principles need to be adhered to, so that such framework could properly aid decision towards sustainability. As a result, Gibson et al., (2005); Reed et al. (2006); and Haapio (2012); Hacking and Guthrie (2008) identified the following key principles: (i) Change in unsustainable practices by advocating that projects, plans, and development contribute to desirable and durable future; (ii) Adequate coverage by integrating all issues that influence our prospects for a sustainable future; (iii) Seek mutually reinforcing gains and minimize trade-offs; (iv) Context-specific; (vi) Public participation in its development; (vii) Not be a deviation from the national bibliography, recommendations, national regulations, building codes, cultural heritage, way of living, and building culture.

However, the Bellagio Sustainability Assessment Measurement Principles (STAMP) has remained the most widely acknowledged principle for sustainability assessment which offers a helpful and holistic guideline for Sustainability Assessment (Pinter et al., 2012). The Bellagio's principle (as it was initially referred to) which dates to 1996 was a product of the harmonization among various field experts in a meeting held in Bellagio, Italy (Sala, et al., 2015). It was developed in response to the need to seek for better ways and procedure for evaluating sustainable development as canvassed by the World Commission on Environment and development (WCED) in 1987 (Devuyst, 2000). The Bellagio STAMP comprises of eight principles for consideration in developing an assessment framework. Guiding vision: Sustainability assessment is driven by sustainability (Pope et al., 2004). As such, any attempt to develop a sustainability assessment framework should be propelled by the need to deliver sustainability. There is a global sustainability vision as well as the local vision which is peculiar to the location where the assessment framework is to be applied. A sustainability assessment framework therefore has a dual role of pursuing and enhancing the global vision as well as defining the specifics of sustainability within a particular context (Gibson et al., 2005).

Essential consideration: This principle advocates that an assessment framework adopts a holistic and comprehensive approach to sustainability (Pinter et al., 2012). It recommends the need to gauge sustainable development beyond the Triple Bottom Line (TBL) to how issues that affect social wellbeing and health are interconnected with concern for preservation of the biodiversity (Gibson, 2001; Srinivasan and Komeily, 2015).

Adequate scope: This principle advocates three main issues for an assessment framework. One, the need to achieve both short and long term targets. Two, to be built on the existing statutory and legal framework (Berardi, 2011; Haapio, 2012). Three, to cover the whole design process. (PCRS, 2010)

Framework and indicators: An important starting point in conceptualizing sustainability assessment is to develop a conceptual framework that lists the issues to be evaluated; the priorities 
of the stakeholders; and the context within which the indicators are to be applied (Pinter et al., 2012). This is necessary in order to develop an assessment framework that will be context-specific while addressing local needs and aspirations in line with Agenda 21.

Transparency: This principles raises the question of the transparency of the assessment process. The success of an assessment framework depends on its transparency. It should not give room for any doubt by the users. The assessment framework should be fair to all with no sentiments. Transparency according to Srinivasan \& Komeily (2015) addresses two issues: One, the need for the public to understand the data and methods employed coupled with the assumption on which assessment process is built. Two, an assurance to the public that the assessment results are reliable and can be trusted.

Effective communication: A sustainable assessment framework must be developed in a clear and simple language that is easy to understand by the majority. It must be free from ambiguity and high technicality to enhance its usage (Pinter et al., 2012). Ideally, it should be user-friendly with quick interpretation and understanding of its result.

Broad participation: Robust stakeholders' participation determines the comprehensiveness, acceptability, and efficiency of an assessment framework (Sala et al., 2013). This principle calls for the involvement of the various stakeholders to ensure that diverse needs are captured and harmonized. Stakeholders' participation in the development in the development of a sustainability assessment framework is of three different stages (Sharifi \& Murayama, 2013). Firstly, stakeholders may be involved at the time of defining the sustainability targets, selection of core criteria and indicators. Secondly, at the stage of weighting the various criteria, the participation of stakeholders is essential. A consensus-based weighting can aid and promote the assessment process (AlWaer et al., 2008). Lastly, citizens and stakeholders can also participate by supplying the necessary feedback for relevant updates and review of the assessment framework.

Continuity and capacity: This principle according to Pinter et al. (2012) advocates that an assessment framework will require repeated measurement, responsiveness to change, investment to develop and maintain adequate capacity, and continuous learning and improvement. This involves a periodic review in terms of progress achieved. The feedback from stakeholders will be a major source of information in this instance.

It is however noteworthy, that although the Bellagio STAMP has been widely accepted by various scholars as a guide for sustainability assessment (Pinter, 2009; Pinter et al., 2012), itsthe operationalization of the Bellagio STAMP is an area yet to be explored in theory or in practice for planning at the neighbourhood level). Shortall et al. (2015) explored the Bellagio STAMP as a methodology for designing a sustainability assessment framework for geothermal energy developments. Also, while there is an extension of sustainability to the neighbourhood level with the emergence of numerous neighbourhood assessment methodologies as established in section 2.1, there is need to examine how these compare across regions using the Bellagio STAMP as an analytical feamework. having examined sustainability assessment and its application at the neighbourhood level in section 2.1, it is quite necessary to inquire how the assessment frameworks align with the Bellagio STAMP. This is a study that has not been conducted, which brings the originality to this study. Furthermore, reviewing the assessment frameworks with the Bellagio STAMP would help in three ways. One, explore its application as a guide for sustainability 
assessment. Two, identify areas for improvement in selected assessment frameworks. Three, to lay a foundation for future conceptualization of an assessment framework that could direct decision towards sustainability in context where a neighbourhood sustainability assessment framework has not yet been conceived

\section{METHODOLOGY}

Data required for this study was obtained primarily from the technical manuals of selected assessment frameworks through document analysis. The selected assessment frameworks are: BREEAM Communities 2012; LEED ND V4; Pearl community rating system (PCRS); and Green Star communities. The choice of these frameworks is as a result of their geographical locations. BREEAM Communities used in UK (Europe); LEED ND in USA (North America); PCRS in UAE (Asia); Green Star Communities in Australia.

The document analysis as a research method involves obtaining data from existing documents such as official gazettes, policy documents, newspapers, and journal publications among others through a process of reviewing and evaluation (Bowen, 2009). Its appropriateness for this study is that it allows data which are readily available to be well examined and interpreted so as to give it meaning, and gain deeper understanding. Also, the benefits of document analysis such as costeffectiveness, lack of obstructiveness to the research process, stability, exactness, broad coverage as posited by Yin (1994); Merriam (1988), and Bowen (2009) enhance its adoption for this study.

Consequently, this study reviewed the technical manual of each of the selected assessment frameworks to get precise information of: its vision; assessment scope and stages; relationship with key policy documents; and the involvement of stakeholders in its development among others. Also, the criteria of the assessment frameworks were categorised to provide a basis for reviewing the frameworks. This was developed using stated purposes of the criteria and indicators as a basis for the re-categorisation. Previous studies (Haapio, 2012; Sharifi and Murayama, 2013; and Wangel et al., 2016) were helpful in this regard. In all, the criteria in the selected assessment frameworks were redistributed under 6 main categories while the degree of consideration for each category in the assessment framework was calculated (table 1). For example, BREEAM Communities allocated $9.3 \%$ of its total weighting to 'Governance' while LEED ND allocated $34 \%$ to issues relating to 'Environment and resource efficiency'.

\section{Table 1 here}

In terms of epistemological position, this study aligns with positivism which suggests that knowledge can only be sourced through observation and measurement. Also, in this philosophical stance, the researcher is limited to only data collection and interpretation in an objective way. This is appropriate for this study as it involved data collection from technical manuals of selected assessment frameworks which are further examined and interpreted using the Bellagio STAMP.

The reliability of the data sourced was ensured by using the technical manuals of the selected assessment frameworks which are available and readily accessible to the public. This ensures consistency with similar studies (Wangel et al., 2016; Sharifi and Murayama, 2013). The validity of the study was ensured in two ways. One, document analysis seemed to be the appropriate data 
collection method as it allowed this study to get the detailed information required of each of the selected assessment frameworks. Two, the geographical spread of the assessment frameworks ensures capturing of context-related issues.

\section{RESULTS}

This section presents the result of the review of the selected neighbourhood sustainability assessment frameworks using the Bellagio STAMP.

\section{Vision}

The vision of the selected Neighbourhood Sustainability Assessment tools aligns with the overall aim of sustainability. It is noteworthy that each of the assessment frameworks included a local vision which has to do with the sustainability challenges peculiar to that context. For example, LEED-ND V4 addresses the issue of urban sprawl which has been a dominant urbanization problem in the United States with the inclusion of a mandate to enhance smart growth, and new urbanism in addition to green infrastructure and buildings.

\section{Essential consideration}

In the selected assessment frameworks, the category of 'environment and resource efficiency' has the highest percentage of indicators. BREEAM Communities allocates 32.4\%; LEED ND- 34\%; PCRS- 57.4\%; and Green Star communities- 25\% (table 1) because most of the selected assessment tools were 'spin-offs' of existing building environmental assessment (BEA) tools (Sharifi and Murayama, 2013). As a result, few modifications were carried out when then assessment frameworks were expanded to the neighbourhood scale. In addition, to ensure some acceptable level of sustainability, BREEAM Communities, LEED-ND V4, and PCRS have 'mandatory criteria' (table 2) which are 'unavoidable' and are compulsory before a new development can be certified. That is, they are not tradeable. The BREEAM Communities certificate for example will not be issued to a development without addressing all the mandatory criteria (BRE, 2012). Mandatory criteria are referred to as 'prerequisites' in LEED-ND and 'required credits' in PCRS. LEED-ND V4 and PCRS do not assign a score to the mandatory criteria, whereas BREEAM Communities does. Green STAR communities however do not have mandatory criteria which gives room for criteria hunting and trade-offs.

\section{Table 2 here}

\section{Adequate scope}

A review of the selected neighbourhood sustainability assessment frameworks showed that this principle was not considered in their development. Although, the frameworks are quite useful for ex-ante assessment, there was no proper consideration for the ex-post evaluation which attempts to assess the performance of the development after certain period of time. According to Wangel et al. (2016), the existing assessment frameworks focused on the process and features indicators which are mainly to either assess the consideration of a specific process with the aim of improving 
sustainability performance (process) or whether specific measures, or solutions will be in place (feature).

\section{Framework and Indicators}

This principle suggests the consideration of the local context in the development of the framework and identification of indicators. In the selected neighbourhood sustainability assessment frameworks, there was consideration for the local context in the choice and selection of indicators (table 3).

\section{Table 3 here}

Whether the indicators satisfied the essential requirements of an indicator was assessed aside from being context-specific. The selected assessment frameworks were able to integrate partially the social, economic, environmental, institutional, and other dimensions of sustainability in the framework. Also, BREEAM Communities and PCRS took into consideration existing policy documents (statutory and legal requirements) in their structure. In BREEAM communities for example, the Environment Impact Assessment (EIA), Noise Impact Assessment, and flood risk assessment among other statutory requirements are to be conducted before a proposed development will be considered for certification (BRE, 2012). The PCRS (for Estidama) also made compliance to the Plan 2030 and other Urban Planning Council (UPC) policies compulsory for any development.

\section{Transparency and effective communication}

The selected assessment frameworks have their manuals available to the public where the stages and steps required for an assessment are explained. Aside from this, documents that needs to be submitted prior to the assessment stages are well stated. How effective an assessment framework communicates to its users can also be measured or determined in the presentation of its results. The final result should give a brief summary of what is happening, while also aiding decisionmaking, evaluation of actions, and also indicating the level attained towards sustainability (Sharifi and Murayama, 2013). In the selected assessment frameworks, results can easily be obtained by simple arithmetic and not by complex calculations. The final results and certifications attained are also very clear in meaning.

\section{Broad participation}

The development of the selected neighbourhood sustainability assessment frameworks was expertled with non-involvement of the public raising the question of its acceptability by non-experts or the public. Green star communities was developed by a conglomerate of 46 industry and government peer reviewers; 15 government sponsors (including all government land organizations); and 10 industry sponsors (GBCA, 2010). LEED ND adopted similar approach in its development by engaging representatives from three particular organizations which are the U.S Green Building Council (USGBC), the Congress for the New Urbanism (CNU), and the Natural Resources Defence Council (NRDC). BREEAM communities which was developed by BRE 
Global Limited is another expert-led initiative, which involved a panel comprising range of experts to assess BRE Global limited standard schemes to ensure a robust assessment framework (BRE, 2012). The Pearl community rating system also adopted the expert-led approach as it was developed by the Abu Dhabi Urban planning council (AUPC).

\section{Continuity and capacity}

This principle advocates for continuous update of assessment frameworks which is needful for progress. BREEAM Communities has two versions (2008 and 2012). Also, LEED ND released in 2009 was upgraded with the release of the LEED ND V4 in 2016. The PCRS developed in 2010 is yet to the upgraded while the Green STAR communities has Pilot versions 0.0 released in 2012; 0.1 in 2014; 0.2 in 2015; versions 1.0 in 2015; and 1.1 (2016).

\subsection{DISCUSSION AND CONCLUSIONS}

This paper reviewed selected neighbourhood sustainability assessment frameworks using the Bellagio STAMP. Although, none of these assessment tools were tailored to suit the Bellagio STAMP in the process of their development, they align satisfactorily well with the principle. However, some weaknesses were discovered. The principle of broad participation (i.e. engagement with stakeholders) was not thoroughly considered in the selected assessment frameworks. The normative effectiveness of sustainability assessment (Bond, et al., 2013) which canvassed for knowledge sharing and social learning can only be enhanced, where there is a forum for engagement and dialogue among various stakeholders. This broad participation ensures striking a balance and harmonizing the diverse needs of the stakeholders.

Stakeholders' involvement ideally should be embedded in the development process in a transdisciplinary setting which can result to co-production of knowledge from problem definition towards solution (Sala, et al., 2015). Sustainability Assessment should encourage public participation by being open and broadly engaging. It must not be a technical exercise or be expert led as it should be a matter of public choices among options and objectives for a desirable and lasting future while it also strengthens the participative potentials of citizens and civil society organizations (Gibson, et al., 2013; Reed, et al., 2006).

Consideration of the local context is essential in developing a Neighbourhood Sustainability Assessment Framework. Sustainability Assessment must in every application continue to respect the peculiarity of the context by specifying the effective criteria for evaluations and decision making in cognisance of the key desires, needs, capacities, and concerns of the locality involved (Gibson 2013). The consideration for local indicators is noteworthy in some existing assessment frameworks. BREEAM Communities and the Pearl Community Rating System considered the existing policy documents in the context they are been applied as canvassed by Haapio (2012) and Berardi (2011).

Issues relating to governance, and economic wellbeing were not well considered in the assessment frameworks. Sustainability Assessment requires a balanced treatment of sustainability issues (Komeily and Srinivasan, 2015). The Assessment framework must ensure adequate coverage by 
integrating all issues that influence prospects for sustainable future. In addition, it must seek mutually reinforcing gains by being a vehicle for appreciating the interdependence of ecology, economy, and the society in a way that are reinforcing to generate a harmonized environment (Gibson, 2013).

In conclusion, as it can be inferred from the study, the Bellagio STAMP provided an efficient and holistic analytical framework for reviewing the selected assessment frameworks. While the context-specificity of sustainability has well been argued in literature (Joss, et al., 2015; Du Plessis, 1999), the transferability of existing frameworks is unrealistic. However, the Bellagio STAMP served as a common reference for reviewing the assessment frameworks. Consequently, the following research implications can be identified. One, , the adoption of the Bellagio STAMP as a global methodological framework can perhaps serve as a guideline for the development of sustainability assessment frameworks most especially in developing countries where there is yet to evolve a definition of systems and criteria for assessing urban neighbourhoods. Berardi (2011) and Yigitcanlar et al. (2015) have canvassed for the development of criteria for assessing neighbourhood sustainability in developing countries. Two, the findings further stressed for the involvement of all stakeholders in the review and update of the existing assessment frameworks. This is needed to capture local values, perceptions, and aspirations. Three, this study by operationalizing the Bellagio STAMP has the potential to increase its knowledge amongst the built-environment professionals and its usage in sustainable neighbourhood planning and design. Four, how the selected assessment frameworks align with the Bellagio STAMP practice-wise need to be investigated which is beyond the scope of this paper. This includes the transparency of the assessment process; and the understanding of assessment framework by the public (non-experts) amongst others.

\section{References}

Adewumi, A.S, AlWaer, H, \& Onyango, V. (2017) Conceptualizing sustainable neighbourhoods through collaborative place making. World Sustainable Built Environment (WSBE) Conference. Hong Kong. 2555-2560

AlWaer, H., \& Kirk, R. (2015) Matching a community assessment tools to the requirements of practice. Proceedings of the institution of civil engineers: Urban design and planning. doi:10:1680/udap.15.00001.

AlWaer, H., Bickerton, R., \& Kirk, D. (2014) Examining the compnenets required for assessing the sustainability of connunities in he UK. Journal of Architecture and planning research, 1-36.

AlWaer, H., Sibley, M., \& Lewis, J. (2008) Different stakeholders' perspectives on sustainability assessment. Architectural Science Review, 51(1), 48-59.

AUPC. (2010) The Pearl Rating Syatem for Estidama. Abu Dhabi: Abu Dhabi Urban Planning Council. 
Berardi, U. (2011) Beyond Sustainability Assessment: Upgrading topics by enlarging the scale of assessment. International Journal of Sustainable Building Technology and Urban Development, 2, 276-282. Retrieved from http://link.springer.com/article/10.1007/s10668-013-9462-0/fulltext.html

Berardi, U. (2013) Sustainability assessment of Urban communities through rating systems. IEnvironment development and sustainability, 1573-1591.

Bond, A., Morrison-Saunders, A., \& Howitt, R. (2013) Framework for comparing and evaluating sustainability assessment practice. In A. Bond, A. Morrison-Saunders, \& R. Howitt (Eds.), Sustainability assessment: Pluralism, practice, and progress (pp. 117-131). London: Routledge.

Bowen, G.A (2009) Document Analysis as a Qualitative Research Method. Qualitative Research Journal, 9 (2), 27-40.

BRE. (2012) BREEAM Communities: Technical Manual SD202-01-2012. Watford: Building Research Establishment.

Cashmore, M., \& Kornov, L. (2013) The changing theory of Impact Assessment. In A. Bond, A. Morrison-Saunders, \& R. Howitt (Eds.), Sustainability Assessmenr: Pluralism, Practice, and Progress (pp. 18-33). London: Routledge.

Deakin, M., \& Curwell, S. (2004) The BEQUEST Framework: the Vision and Methodology of a Collaborative Platform for Sustainable Urban Development. Geneva: EnviroInfo. Retrieved 05 15, 2016, from http://enviroinfo.eu/sites/default/files/pdfs/vol110/0091.pdf.

Devuyst, D. (2000) Linking impact assessment and sustainable development at the local level: The introductory of sustainability assessment system. Journal of sustainable development. 8(67-78), 67-78.

Du Plessis, C. (1999) Sustainable development demands dialogue between developed and developing worlds. Building Research and Information, 27(6), 378-389.

GBCA. (2012) Green Star Communities: Guide for Local Government. Melbourne: Green Building Council Australia.

Gibson, R. (2001) Specification of sustainability-based environmental assessment decision criteria and implications for determining "significance" in environmental assessment. Canadian Environmental Assessment Agency Research and Development Programme. Retrieved from http://static.twoday.net/NE1BOKU0607/files/Gibson_SustainabilityEA.pdf.

Gibson, R. (2013) Why sustainability assessment? In A. Bond, A. Morrison-Saunders, \& R. Howitt (Eds.), Sustainability Assessment: Pluralism, Practice and Progress (pp. 3-17). London: Routledge. 
Gibson, R., Hassan, S., Holtz, S., Tansey, J., \& Whitelaw, G. (2005) Sustainability Assessment: Criteria, Processes and Application. London: Routledge.

Giradet, H. (2015) 'Ecopolis'- The regenerative city. In Low Carbon Cities (pp. 59-74). Oxon: Routledge.

Haapio, A. (2012) Towards sustainable urban communities. Environemntal Impact Assessment Review, 32, 165-169.

Joss, S., Cowley, R., de Jong, M., Muller, B., Park, B., Rees, W., . . Rydin, Y. (2015) Tomorrow's City Today: Prospects for Standardising Sustainable Urban Development. London: University of Westminster.

Komeily, S., \& Srinivasan, R. (2015) A need for a balanced approach to Neighbourhood Sustainability Assessment. Journal of sustainable cities and society, 18, 32-43. doi:10/1016/j.scs.2015.05.004.

Merriam, S.B. (1998) Case study research: A qualitative research. San Francisco: JosseyBass.

Pinter, L. (2009) Bellagio STAMP. $3^{\text {rd }}$ World Forum on measuring the progress of societies. Retrieved 10 19, 2018, from http://www.oecd.org/site/progresskorea/44117794.pdf

Pinter, L., Hardi, P., Martinuzzi, A., \& Hall, J. (2012) Bellagio STAMP: Principles for Sustainability Assessment and Measurement . Ecological Indicators, 17, 20-28.

Pope, J., Annadale, D., \& Morris-Saunders, A. (2004) Conceptualising Sustainability Assessment. Environmental Impact Assessment Review, 24, 295-616.

Reed, M., Fraser, E., \& Dougill, A. (2006) An adaptative learning process for developing and applying sustainability indicators with local communities. Ecological Economics, 406418.

Roberts, P. (2009) Sustainable Communities: Policy, Practice and Professional Development: A Model for Europe. In S. M. Cooper I (Ed.), Sustainable Urban Development: Changing Professional Practice (pp. 127-144). Oxon: Routledge.

Sala, S., Ciuffo, B., \& Nijkamp, P. (2015) A systemic framework for sustainability assessment. Ecological Economics, 119, 314-325.

Sharifi, A., \& Murayama, A. (2013) A critical review of seven selected Neighbourhood Sustainability Assessment tools. Environmental Impact Assessment Review, 38, 73-87. doi:10.1016/1.eair.2012.06.006.

Shortall, R, Davidsdottir, B, \& Axelsson, G. (2015) Methodology for Designing a Sustainability Assessment Framework for Geothermal Energy Developments. Proceedings World Geothermal Congress. Melbourne, 1-10 
USGBC. (2016) LEED ND V4 for Neighbourhood Development. Washington: US Green Building Council.

Wangel, J., Wallhagen, M., Malmqvist, T., \& Finnveden, G. (2016) Certification systems for sustainable neighbourhoods: What do they really certify? Environmental Impact Assessment Review, 56, 200-2013.

Warren-Myers, G., Judge, M., \& Paladino, A. (2018) Sustainability ratings in residential development: a worthwhile endeavour? International Journal of Building Pathology and Adaptation, 36(4).

Yigitcanlar, T., Kamruuzaman, M., \& Teriman, S. (2015) Neighbourhood Sustainability Assessment: Evaluating Residential Development Sustainability in a Developing Country Context. Sustainability, 7, 2570-2602.

Yin, R.K. (1994) Case study research: Design and methods (2nd ed.). Thousand Oaks, CA: Sage. 